\title{
The Application of Smart Textiles in the Brand Fashion Design
}

\author{
Hong-Ying Deng ${ }^{1, a}$ and Yu-Mei Cui ${ }^{2, b}$ \\ ${ }^{1}$ College of Fashion and Design, Donghua University, West Yan'an Road No.1882, Shanghai, China, 200051 \\ ${ }^{2}$ College of Fashion and Design,Donghua University, West Yan'an Road No.1882,Shanghai, China, 200051 \\ aypnypj@126.com, bcymyhyez@126.com
}

\begin{abstract}
With the economic and social development, material life in the era of abundance is not only in meeting the basic needs of life, but also modern consumers become forced to pursue the spiritual and cultural needs. On the other side, clothing will not just fulfill the basic functions of beauty and suitability, thus, more consumers begin to pay closer attentions to apparel textile's individuation expression and technological elements, or to some other deeper emotional requirements etc. Smart textiles originally belongs to the cutting-edge scientific field of fashion industry, however, with the booming development of internet industry and smart phone devices, acute apparel manufacturers must have to take a ride on advanced tech-trends and launch a wide expansion of smart textile fibres's applications into the clothing industry. This thesis would present a basic introduction on the concept and classifications of the smart textile fibres, and then like to deploy a profound analysis of smart textiles applied in the brand fashion design.
\end{abstract}

Keywords: Smart Textiles, Brand, Fashion Design, Technology and Internet.

\section{Introduction}

The wearable smart technology has always been concerned among the computer academia and industry. Because its high cost and technical sophistication, most of all for its comparably low consumption demands, wearable smart mobile devices has just remained at the conceptualization phase. Along with the development of mobile Internet, advanced technology and the rising concerns of the fashion industry on the smart textiles, this newly-type textile materials then begin to come upon on a commercial mode. For example, international technology giants (like Google or Apple) have increased wearable technology investment into the fashion design field, which in turn, the whole fashion industry would then correspondingly gain several inspirations. Manufactures of different levels of clothing markets, no matter the mass market or Paris's haute couture, all have to anticipate in a more intense market competition. Textile materials, as the most basic component of fashion design, play a key role, therefore, some famous designer brands almost ready to launch a full swing, boldly apply the smart textile fibres, which being easy to human body, for their target to improve the odds on increasing the sales amounts in the fierce commercial battle.

\section{A basic introduction to smart textiles}

\subsection{A Basic Concept of Smart Textiles}

The so-called intelligence refers that clothing obtains the function of reading human body's language, or by saying, clothing functions would change with the changing human body and environment. It is an indication that intelligent apparel forms the functions of saving energy and information but also conveying or transferring. ${ }^{[1]}$ Smart textiles means the simulation of living bio-system, and meantime both combines with perceiving and driving actions. More specifically, this type of textiles cannot just perceive a subtle alteration at the inner state or the outer atmosphere, but also through itself feedback mechanism responses simultaneously changes of the properties as expected. Perception, feedback and response, the main three elements, altogether make up smart materials. Smart textile materials defines as an immediate response stimulated by environmental conditions or other factors, but temporarily still retains the inherent nature and clothing functions. ${ }^{[2]}$

\subsection{The Main Classifications of Smart Textiles in the Apparel Application}

The production of clothing by smart textiles has possessed additional functions in the daily life or work routine; as a consequence, smart textile material would 
become more focused and popular. Smart textile fibres and fabrics could stimulate the outside environment(such as heat, chemistry, light, humidity, machinery, electromagnetism etc.), good self-adaptive, self-judging, and self-healing abilities actually cannot also lack either. ${ }^{[3]}$ In general, smart textile fibres has main classifications as followed: memory fibres, cameleon fibres, thermo-regulated fibers, smart gel fibres and electronic intelligent fibers, etc.

\subsection{The Development Tendency of Smart Textiles}

Nowadays, smart textiles have been at a state of rapid advance along with the development of science and technology, especially the wide population of internet technology and smart mobile devices has forced intelligent textiles to come into the mass marketization. From early period's single function to multi-purpose directions, it again combines technology of smart mobile devices and Bulk data handling techniques, then develops multi-functions: health monitoring, media entertainment system, GPS position(Global Positioning System) etc, which formerly needs to be configured separately by certain electronic equipment.

Green and Environmental Protection still stays a constant theme in the near future, naturally, the development of smart textiles should coherently run towards an ecological green direction. Apparel manufacturing process must be strictly under the scientific monitor and detection without causing any harm to human beings and environment, thus, how to convert sustainable, recycled, reclaimed materials to smart textiles would be a must future tendency and important research direction.

\section{The Application Analysis of Smart Textiles in the Brand Fashion Design}

\subsection{The Importance of Smart Textiles' Application in the Brand Fashion Design}

Under the background of economic globalization, information and techniques and technology would no longer be the barriers between competitors among the clothing enterprise. And nowadays as for a more heated white-hot competition in the international fashion market, customers behave more particular about products influenced by individual, scientific frontier philosophy. Therefore, fashion brands cannot only rely on the marketing team to make up a fantastic and touching thematic story, or just struggle to find a catchy phrase, or say a single core item cannot meet complete needs of target customers, which has not attached any extravagant hope to it. At present, consumers become more concerned about the visual effects and comfort index when dressing clothes, to more excitements, it could not be better when affording fancy high-tech products experiences.
In terms of the applications of smart textiles, the most commonly known one is the space suit wearing by space astronauts. It is undeniable that a space suit is a mixture of the most advanced sci-tech levels which smart textiles can keep, but in the daily life smart textiles become most widely applied by some sports clothing brands. For example, at the World Cup Brazil in 2014, PUMA put $A C T V$ (a type of sport elastic tape) into the clothes, which could provide a massage function with a slight effect of strength. It even helps working muscles deliver energy more quickly and efficiently, then sequentially boosting players' match performance. In 2012, Hot pants launched by Adidas were developed especially for British cycling team, this statement racing suit can be conductive to keeping warm temperature of athletes, then obtain more sustained motivation. [4] Sports brands become the foregoers of applying smart textiles, which also proves that the application of smart textiles plays a more important role in the brand fashion design.

\subsection{Smart Textiles' Brand Clothing to be a Consumers' Demand}

Today in the 21 st century, modern people praise highly lifestyles of personality, high-tech and intelligence; intellectualization gradually develops into an inevitable tendency. Daily trips or maintenance can be wholly implemented by smart mobile devices with just a swipe of your fingers. On the other hand, particular intellectualization of clothing to a great extent would stride to be more popularized or routinized. For instance, Madura from India has recently released Icetouch series shirts, which can react to lower body surface temperature by five degree and play a function of intelligence temperature control. In addition, famous lingerie brand Victoria's secret has also launched a functional bra of Incredible combined with Heart Rate Monitoring band, and it could check for heart rate concurrently, which in turn escort for body health.

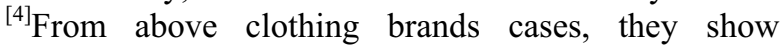
willingly to adopt smart textiles to meet consumers' higher needs, therefore, without any exaggeration, it proves to be a role of boosting the application of smart textiles among fashion industry.

\section{Features of Smart Textiles as a Perfect Interpretation in the Brand Fashion Design}

\subsection{The Recreational function of Smart Textiles in the Brand Fashion Design}

The integration of music and apparel makes the application of smart textiles more fresh and amusing; there is no doubt that music has been an essential way of entertainment and leisure for most in the daily life. Though music player can be made to be a small and exquisite looking, yet try to imagine, if what we dress 
itself can furnish like a music player, it appeals promising market attractiveness factors among young communities. Now in Europe, famous jeans brand Levi's has just popularized such a music jacket. Even more wonderful, it can be provided as FM radio including saving and playing functions. For the purpose of such mentioned functions, it needs additional energy to absorb solar energy, wind energy, thermal energy and other physical energy sources, which altogether perfectly interprets smart textiles' wide applications in the brand fashion design. Moreover, Alyce Santoro personally invented an innovative Sonic fabric, the sonic is a durable and versatile audible fabric made from $50 \%$ recycled polyester and $50 \%$ reclaimed audio-cassette tape, which is formed by the hues of the polyester warp combined with the cassette tape weft. It is extremely durable, but also remarkably soft even with a sparkly sheen. The strands of tape could form a collage of sounds, such as, Beethoven, the Beatles, and sounds collected in the Peruvian rain forest etc.

\subsection{The Health Care Function of Smart Textiles in the Brand Fashion Design}

Scientists make an attempt to insert embedded photoconduction fibres into clothing fabrics, and then this sort of smart textile fibres can anytime inspect human beings' heart rate and respiratory rate. It certifies a concentrated embodiment and main symbol about smart textile fibres's medical care values. For example, American Textronics has already introduced the technology to produce several items of underwear or sport suit, equipped with functions of checking heart rate, respiratory rate, temperature and blood pressure or other life cycle information. Once this type of smart clothes was widely used for prevention from SIDS(Sudden Infant Death Syndrome ) ${ }^{[5]}$. In all, it passes for a perfect annotation on the promising application of smart textiles in the brand fashion design.

\subsection{The High-tech Features of Smart Textiles in the Brand Fashion Design}

Smart Textiles incorporates with many relevant fields of high-tech, such as, Bulk data analysis technology, sensor technology, wireless network technique and etc. After adding special performance of materials, smart textiles can then turn into a data receiver formed by numberless sensors, which by virtue of combining wireless network technique and smart phones or computers finally achieve real time GPS positioning. However, previously, it only can be implemented functionally by expensive instruments and apparatus for analyzing motion data. For instance, Nike company together hand to cooperate with Google or Apple launch gym shoes, which could track real-time footprints by use of Google Earth, wearing this pair of shoes cannot check movement routes at any time, but control different massive motion data. ${ }^{[5]}$ High-tech features can be greatly combined with smart clothing, which again proves a perfect presentation in the brand fashion design.

\section{Conclusions}

Smart textiles, considered as a new classification of apparel fabrics, simultaneously obtain entertainment, medical care, and other high-tech properties in the integrated; therefore, smart textiles can be served as ideal materials for fashion designers. However, smart textiles have just been applied at an initial stage. Internet technology's soaring development, Bulk Data widening application, and more concentrations by modern people, smart textiles still has a vast market prospect. For the sake of brand clothing becoming received by more market favors, how to develop smart textile fibres tends to be a step of necessity.

\section{References}

1. Zhu Songwen, The New Development of Clothing Fabrics, Cotton Textile Technology, 1999.08.

2. Cao Lihui, A Research on the Development and Application of Smart Clothing Fabrics, Journal of Zhejiang Textile \& Fashion Vocational College, 2010.09:No.3.

3. Yao Lianzhen, Yang Wenfang, Qiao Yanli, The Research Progress of Smart Textile Fibres and Fabrics, Textile Printing: Textile College of Tianjin Polytechnic University, 2012.No.12.

4. Information on http://qtnews.zjol.com.cn/culture/text.asp?id=517 130 .

5. Information on http://gold.hexun.com/2008-10-20/110131964.ht $\mathrm{ml}$. 